\title{
Intervensi Kelompok secara Daring untuk Meningkatkan Kemampuan Menolak secara Asertif di Masa Pandemi Covid-19
}

\author{
Ani Rakhmaningrum ${ }^{1}$, Luh Surini Yulia Savitri ${ }^{2}$ \\ 1,2Fakultas Psikologi Universitas Indonesia \\ Lingkar Kampus raya, Jalan Mawar no 538 Pondok Cina, Beji, Depok, Jawa barat \\ e-mail : anirakhmaningrum@gmail.com¹, luh.surini@ui.ac.id ${ }^{2}$
}

Article History:

Received

22 April 2021

Review

19 Mei 2021

Revised

20 Mei 2021

Accepted

8 Juni 2021

Published

23 Juni 2021

Reviewer A:

Fendy Suhariadi
Abstract. Adolescents are prone to experience peer pressure on their peer group which lead them conforming group's behavior. This condition can lead them doing risky behaviour such as smoking, using drugs, free sex, fighting, stealing, and violating other social norms. In times of this COVID-19 outbreak, the can be pressured to break the rules such as going to crowds, hanging out with friends, or bailing from online school. Preventive action neeeded to prevent adolescents exposed to risk that could endanger their safety. Group intervention program to increase assertive refusal skills in adolescents who are vulnerable to peer pressure is provided. Programs are designed online in order to make this accessible and maintain personal health and safety. Participants felt positive benefit from the program. Statistical analysis showed the program was not effective enough to increase participant's assertive refusal skill, but effective increasing participant's tendency to behave assertively.

Keywords : assertive refusal skill, online group intervention, peer pressure

Abstrak. Sebagian remaja rentan terpengaruh oleh tekanan teman sebaya dalam kelompok yang dapat menyebabkan mereka menujukkan konformitas terhadap perilaku kelompok. Hal ini dapat menjadi cikal bakal terlibatnya remaja dalam perilaku kenakalan seperti merokok, menggunakan narkoba, seks bebas, tawuran, pencurian, dan tindakan melanggar norma lainnya. Dalam masa pandemi COVID-19, tekanan untuk melanggar aturan seperti mengikuti ajakan untuk berkumpul, pergi ke keramaian, dan menyalahgunakan waktu sekolah dapat muncul. Hal ini perlu dicegah agar remaja tidak terkena risiko yang membahayakan keselamatan dirinya. Salah satunya dengan memberikan program intervensi berkelompok untuk meningkatkan kemampuan menolak secara asertif pada remaja yang rentan mengalami tekanan teman sebaya. Program dirancang secara daring agar dapat menjangkau partisipan yang membutuhkan dan menjaga kesehatan serta keselamatan diri. Hasilnya para partisipan merasakan manfaat yang positif, namun hasil analisis statistik menunjukkan program belum cukup efektif meningkatkan kemampuan menolak secara asertif namun terbukti efektif meningkatkan kecederungan berperilaku asertif pada partisipan.

kata kunci : intervensi kelompok daring, kemampuan menolak secara asertif, tekanan teman sebaya 


\section{Pendahuluan}

Masa remaja dikenal sebagai periode yang penuh dinamika. Beragam gejolak yang terjadi dalam diri remaja seperti tidak stabilnya emosi, rasa ingin menarik diri dari keluarga, tantangan di sekolah, dan masalah pertemanan menjadi hal yang lumrah hadir dalam kehidupan remaja. Remaja juga rentan terlibat dalam perilaku kenakalan seperti merokok, menggunakan narkoba, seks bebas, tawuran, pencurian, dan tindakan melanggar norma masyarakat lainnya (Unayah \& Sabarisman, 2015). Ritcher (2010) menyebutkan, perilaku kenakalan remaja memiliki risiko bagi kesehatan dan juga kesejahteraan remaja.

Menurut laporan tahunan dari UNICEF Indonesia tentang situasi anak Indonesia secara umum pada tahun 2020, lebih dari 55,3\% remaja lelaki berusia 15-19 tahun di Indonesia menyatakan telah merokok (UNICEF Indonesia, 2020). Dalam laporan kinerja KPAI tahun 2018, terdapat 1434 anak dan remaja yang berhadapan dengan hukum, dan 679 anak yang terlibat dalam kasus pornografi serta cyber crime. Data dari Badan Narkotika Nasional (BNN, 2018), disebutkan angka penyalahgunaan narkoba di kalangan remaja dari 13 Ibukota Provinsi di Indonesia mencapai angka 2,29 juta orang. Selain itu, dalam hal kerentanan perilaku seksual, diperkirakan sebanyak 47,3\% dari tiap 1000 remaja perempuan di Indonesia pernah melahirkan.

Menurut Dodge, Lansford, dan Dishion (2006), perilaku menyimpang dan kenakalan remaja salah satunya timbul karena adanya tekanan negatif oleh teman sebaya. Remaja seringkali terpengaruh oleh tekanan teman sebaya yang mengarahkan mereka untuk menujukkan konformitas terhadap perilaku kelompok (Ramasamy, Krishnan, \& Tee, 2020). Untuk mendapatkan penerimaan dari teman sebaya, remaja menampilkan perilaku sesuai dengan norma kelompok, walaupun hal itu bertentangan dengan apa yang diinginkan dan dianutnya (Lebedina, Lotar, \& Ricijaš, 2011). Brown dan Clasen (1986) membagi tekanan teman sebaya ke dalam tiga jenis yaitu peer involvement, conformity to peer norms, dan misconduct. Peer involvement yaitu desakan untuk terlibat dalam kegiatan dan hubungan dengan kelompok. Conformity to peer norms, yaitu desakan untuk mengikuti norma-norma yang dianut teman dalam beraktivitas, berperilaku, ataupun gaya hidup. Sedangkan misconduct yaitu desakan untuk melakukan pelanggaran baik terhadap norma hukum, ataupun norma umum yang berlaku di masyarakat.

Terdapat beberapa hal yang mempengaruhi tekanan teman sebaya. Yang pertama adalah usia, menurut Steinberg dan Monahan (2007 dalam Gikonyo \& Njagi, 2016) remaja di rentang usia 11 hingga 15 tahun lebih mudah terpapar tekanan sebaya dibandingkan 
dengan remaja dengan usia yang lebih tua. Sementara itu, remaja dalam rentang usia 15 hingga 18 tahun sudah lebih dapat menunjukkan penolakan terhadap tekanan dari teman sebaya. Jenis kelamin juga memberikan pengaruh. Secara umum, perempuan lebih mengalami tekanan dari teman sebaya dibandingkan laki-laki (Brown, 1982 dalam Gikonyo \& Njagi, 2016). Selain itu, situasi kelas juga menjadi hal yang mempengaruhi terjadinya tekanan teman sebaya, keberadaan teman di kelas memberikan standar dalam berperilaku bagi remaja. Hal ini lalu mempengaruhi atmosfer di dalam kelas, gangguangangguan yang dapat terjadi di dalam kelas, dan level kenakalan yang mungkin ada sehingga mempengaruhi proses belajar di dalam kelas (Gikonyo \& Njagi, 2016).

Dalam masa pandemi COVID-19 ini, remaja tetap rentan terpengaruh tekanan teman sebaya sehingga berpotensi melakukan perilaku yang melanggar aturan seperti mengikuti ajakan teman untuk berkumpul, pergi ke keramaian, dan menyalahgunakan waktu sekolah secara daring. Hal ini perlu dicegah agar remaja tidak terkena risiko yang dapat membahayakan keselamatan diri sendiri, keluarga, dan lingkungan sekitarnya. Karena sebagai makhluk dengan kebutuhan sosial yang tinggi, berada bersama temanteman menjadi salah satu hal yang diinginkan oleh remaja.

Nichols, et.al (2006) memaparkan, untuk mencegah remaja menampilkan perilaku menyimpang akibat tekanan negatif oleh teman sebaya, pemberian program untuk meningkatkan kompetensi sosial dan personal pada remaja merupakan salah satu cara yang efektif. Bentuk kompetensi personal yang dinilai penting untuk ditingkatkan adalah kemampuan untuk menolak secara asertif (assertive refusal skill). Hal ini sejalan dengan pendapat Eipstein, Griffin, dan Botvin (2000) yang menyarakan rendahnya kemampuan menolak secara asertif pada remaja diprediksi dapat meningkatkan kecenderungan perilaku kenakalan seperti merokok, mengkonsumsi alkohol, dan penyalahgunaan narkoba.

Kemampuan menolak secara asertif merupakan bentuk strategi verbal dan nonverbal yang digunakan untuk menolak tekanan langsung maupun tidak langsung pada individu untuk terlibat dalam perilaku negatif (Botvin \& Botvin, 1992; Miller, dkk., 2000). Mengajarkan strategi-strategi untuk menolak tekanan negatif oleh teman sebaya secara asertif dinilai sebagai program pencegahan yang efektif untuk menghindari remaja terjerumus ke dalam masalah yang lebih besar (Nichols, et al., 2006).

Berdasarkan paparan diatas, peneliti menyusun program intervensi kelompok bagi remaja untuk meningkatkan kemampuan menolak secara asertif bagi remaja secara daring. Menurut Leader (1991), Program intervensi dalam kelompok bagi remaja 
memberikan sebuah wadah yang memungkinkan terjadinya perkembangan personal dan interpersonal. Kesamaan antar anggota kelompok dapat membantu mengatasi rasa malu atas pengalaman atau perasaan yang dimiliki remaja, dan juga menciptakan rasa aman untuk dapat saling membuka diri (Leader, 1991). Lalu dengan kondisi Pembatasan Sosial Berskala Besar (PSBB) yang masih di berlakukan, intervensi secara daring melalui internet menjadi pilihan yang dapat dilakukan agar tetap dapat menjangkau partisipan yang membutuhkan tanpa harus keluar rumah agar tetap terjaga kesehatan dan keselamatannya. Internet juga dianggap dapat menjadi media efektif untuk memberikan intervensi kesehatan mental sebab internet menjadi hal yang dapat dijangkau dan tersedia bagi sebagian besar masyarakat saat ini, termasuk para remaja (Kazdin, 2015, dalam Herrero dkk., 2019).

Partisipan dalam penelitian ini adalah remaja yang berasal dari sekolah berbasis agama islam dengan alasan melihat studi yang menyatakan terdapat perbedaan yang signifikan antara sekolah berbasis Islam dengan sekolah umum dalam hal tingkat moral para siswanya dimana siswa pada sekolah berbasis Islam menunjukkan tingkat moral yang lebih tinggi (Utama, 2016), namun kenyataannya masih ditemukan potensi terjadinya tekanan teman sebaya yang berpotensi mengarah ke perilaku kenakalan remaja. Sebagai contoh, Studi yang dilakukan oleh Sa'diyyah (2017) terhadap remaja di sekolah berbasis Islam Jawa Timur menemukan berbagai bentuk kenakalan seperti membolos, meninggalkan pelajaran, dan merokok.

\section{Metode}

Desain penelitian yang akan dilakukan adalah one group pretest-posttest design. Hasil dari penelitian kemudian akan dianalisis menggunakan uji Wilcoxson. Teknik sampling yang digunakan dalam penelitian adalah purposive sampling. Terdapat tiga alat ukur yang digunakan dalam penelitian ini. Yang pertama adalah Peer Pressure Inventory (PPI). PPI merupakan alat ukur berbentuk kuesioner yang dibuat oleh Brown dan Clasen (1985) yang telah diadaptasi oleh Rahel (2014) untuk melihat seberapa jauh individu di kelas 6 hingga 12 mengalami tekanan dari teman sebaya. Yang kedua adalah Skala Tingkah Laku Asertif - Aspek Menolak Permintan (STLA-MP) yang disusun oleh Zulkaida (2004). STLA mengukur tingkah laku asertif berdasarkan berbagai aspek, dalam penelitian ini digunakan aspek menolak permintaan. Alat ukur yang ketiga adalah Skala Tipe Perilaku Asertif (STPA). STPA merupakan alat ukur berbentuk multiple choice yang dibuat oleh Cadogan (1990) dan telah diadaptasi oleh Zulkaida (2004) untuk melihat 
kecenderungan tipe perilaku individu ke dalam tiga kelompok: 1) asertif, 2) non-asertif, 3) agresif.

Partisipan dalam penelitian ini adalah remaja berusia 11-15 tahun, berasal dari sekolah berbasis agama Islam, pernah mendapatkan tekanan dari teman sebaya yang ditunjukkan oleh skor Peer Pressure Inventory (PPI), menunjukkan kemampuan menolak di bawah rata-rata kelompok yang ditunjukkan oleh skor Skala Tingkah Laku AsertifAspek Menolak Permintaan (STLA-MP) atau memiliki kecenderungan berperilaku non asertif dalam kehidupan sehari-hari yang ditunjukkan dari skor Skala Tipe Perilaku Asertif (STPA).

Seluruh rangkaian program intervensi dilakukan secara daring. Untuk merekrut partisipan, pemberi intervensi (PI) melakukan rekruitmen terbuka melalui media sosial. Calon partisipan yang sesuai dengan kriteria lalu dihubungi untuk dikonfirmasi tentang kesediaannya mengikuti rangkaian program. PI lalu juga memastikan masing-masing calon partisipan telah mendapatkan izin dari orang tua untuk mengikuti program ini melalui pernyataan dalam parental consent. Dalam program intervensi ini terdapat 5 orang partisipan yang terdiri dari 3 remaja perempuan dan 2 remaja laki-laki yang tinggal di Jabodetabek.

Program intervensi kelompok untuk meningkatan kemampuan menolak secara asertif ini disusun berdasarkan adaptasi modul yang dirancang oleh Dickson (2016). Pelaksanaan program ini menggunakan prinsip-prinsip experiential learning dari Burnad (1996) dengan bentuk aktivitas berupa penyampaian materi, berbagi pengalaman antar partisipan, diskusi, dan roleplay. Dalam setiap sesinya, PI juga melakukan observasi terhadap partisipan. Hal yang diobservasi dari partisipan antara lain gestur dan bahasa tubuh, partisipasi selama sesi, gaya komunikasi yang digunakan, dan kemampuan yang ditampilkan saat melakukan roleplay. PI juga menyiapkan lembar evaluasi yang diberikan tiap akhir sesi pada partisipan. Lembar evaluasi berisi berisi berisi refleksi terhadap hal penting apa dipelajari dalam sesi tersebut, apakah partisipan merasa terbantu setelah mengikuti sesi, pelajaran yang dapat diterapkan dalam kehidupan sehari-hari, dan masukan untuk pelaksanaan sesi berikutnya. Partisipan juga diminta menyampaikan jika terdapat hal tidak nyaman yang dirasakan selama berlangsungnya sesi.

Program intervensi terdiri dari 4 tahap utama yaitu tahap pre-test, tahap pelaksanaan program, tahap post-test, dan tahap follow-up. Adapun program dirancang memiliki 5 sesi. Pelaksanaan setiap sesi dilakukan melalui aplikasi zoom cloud meeting dengan durasi berkisar antara 45 - 60 menit. Di tiap awal sesi, PI selalu memberikan ice 
breaking agar partisipan lebih relaks dan situasi menjadi lebih hangat. Dalam beberapa sesi, kegiatan juga diawali dengan aktivitas yang bersifat memberikan pengalaman konkrit terkait materi yang akan dibahas dalam sesi tersebut. Setiap sesi memiliki tema dan tujuan yang berbeda-beda.

Tema pada sesi 1 adalah seputar menolak tekanan teman sebaya, sesi ini bertujuan agar partisipan menyadari apa itu tekanan teman sebaya, apa bentuknya, dan bagaimana strategi yang dapat digunakan untuk melakukan penolakan dengan baik. Pada sesi 2, tema yang diangkat adalah mengenal gaya komunikasi. Dalam sesi ini partisipan akan diajak untuk memahami dan mengetahui perbedaan dari berbagai macam gaya komunikasi. Tema pada sesi 3 yaitu strategi melakukan penolakan. Sesi ini bertujuan agar peserta memahami dan dapat mengaplikasikan strategi melakukan penolakan.

Tema pada sesi 4 adalah komunikasi asertif. Dalam sesi ini partisipan akan diajak untuk mengaplikasikan pengetahuan mengenai keterampilan untuk menolak dengan melakukan roleplay antar partisipan. Skenario rolepay yang diberikan adalah contoh tekanan teman sebaya yang mungkin muncul di masa PSBB dan merupakan hal yang seharusnya dihindari misalnya ajakan untuk berkumpul di luar rumah, tidak menggunakan masker saat bepergian, pergi ke mall atau makan di restoran yang ramai.

Sebelum memasuki sesi 5, masing-masing partisipan akan dihubungi secara personal oleh PI untuk diajak melakukan roleplay bersama PI dengan skenario yang terkait ajakan tentang hal-hal yang seharusnya dihindari saat PSBB. Tujuan dari aktivitas ini adalah agar partisipan lebih percaya diri dan terbiasa untuk mengaplikasikan pengetahuan mengenai proses menolak secara asertif. Dalam sesi 5, partisipan akan diajak untuk menemukan insight atas rangkaian sesi yang sudah diikuti sebelumnya. Harapannya para partisipan dapat menarik kesimpulan dan keterkaitan dari sesi-sesi sebelumnya. Rancangan program intervensi ini sudah melewati proses Kaji Etik dari Fakultas Psikologi Universitas Indonesia.

Setelah seluruh tahap program intervensi dilakukan, PI akan melakukan analisis terhadap data kuantitatif yang didapat dari pre-test, post-test, dan follow-up untuk kuesioner STLA-MP dan STPA. Analisis juga dilengkapi dengan data kualitatif yang didapatkan saat sesi terakhir bersama partisipan dan dari form evaluasi yang diberikan.

\section{Hasil}

Hasil program intervensi secara kuantitatif dapat dilihat dalam gambar berikut: 
ISSN 2580-6076 (Print), ISSN 2580-8532 (Online)

Gambar 1. Diagram Perbandingan Skor STLA-MP

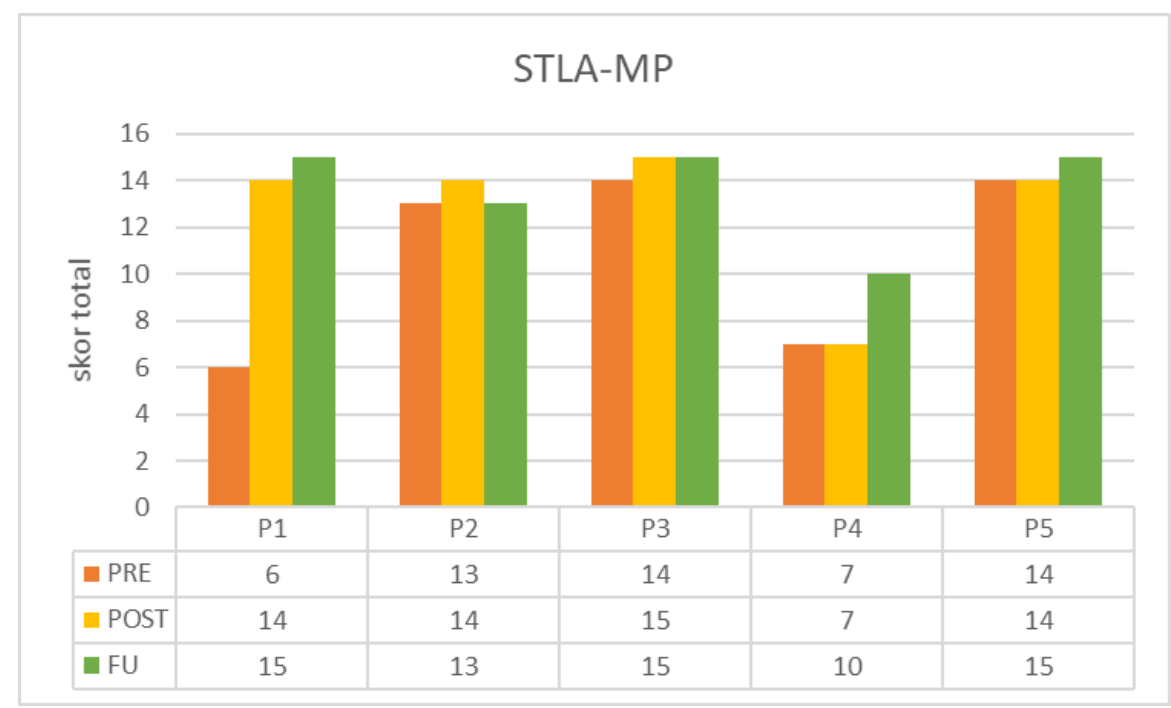

Berdasarkan data pengisian kuesioner STLA-MP oleh partisipan saat pre-test dan posttest, 3 dari 5 partisipan mengalami kenaikan skor tingkah laku menolak asertif untuk aspek menolak permintaan. P1 menunjukkan kenaikan skor paling tinggi sebanyak 8 poin. P2 dan P3 menunjukkan kenaikan skor sebesar 1 poin. Sedangkan P4 dan P5 tidak menunjukkan perubahan skor. Hasil saat follow-up menunjukkan 3 partisipan mengalami peningkatan skor STLA-MP dibandingkan dengan skor saat post-tes (P1,P4,P5), 1 orang partisipan mendapatkan skor yang konsisten dibandingkan dengan post-test (P3), dan 1 orang partisipan mengalami penurunan skor 1 poin dibandingkan dengan post-test (P2) sehingga mendapatkan skor yang sama seperti skor saat pre-test.

Gambar 2. Diagram Perbandingan Skor STPA

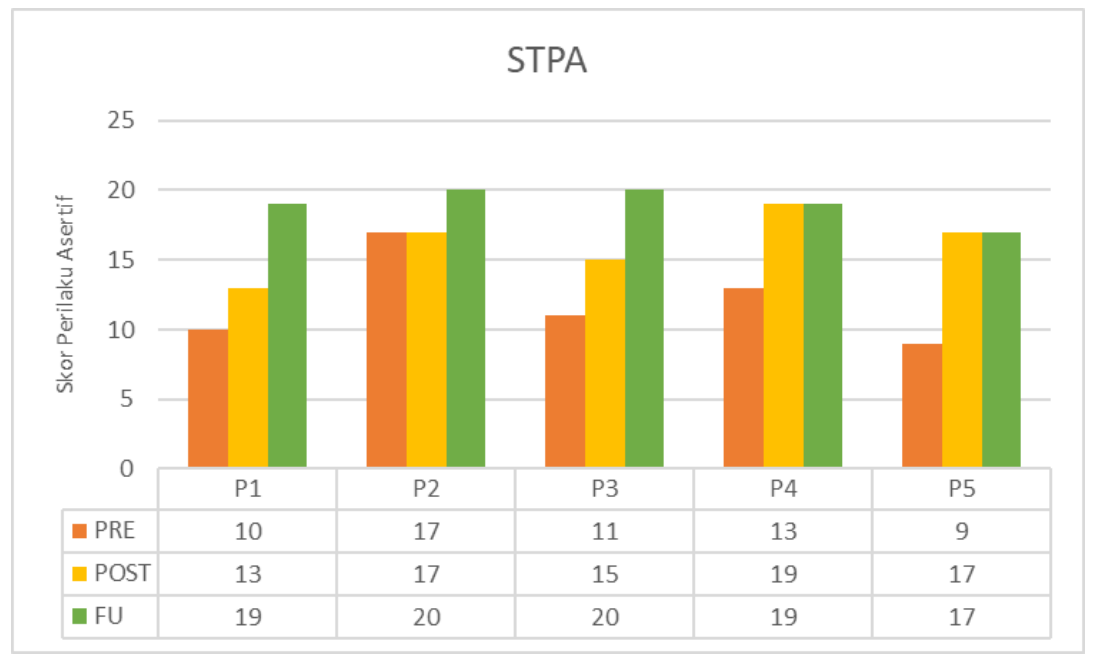

Berdasarkan hasil skor STPA saat pre-test dan post-test, 4 orang partisipan menunjukkan peningkatan skor tipe perilaku asertif (P1,P3,P4,P5), sedangkan P2 tidak menunjukkan 
perubahan skor. Hasil perbandingan skor post-test dan follow-up menunjukkan 3 orang partisipan menunjukkan peningkatan skor STPA (P1, P2, dan P3), sedangkan 2 partisipan menunjukkan skor yang konsisten antara post-test dan follow-up (P4,P5).

Hasil analisis statistik dengan menggunakan uji wilcoxson terhadap pengukuran STLA-MP dan STPA saat pre-test dan post-test menunjukkan hasil sebagai berikut :

Tabel 1. Hasil Uji Wilcoxson Pre-test dan Post-test

\begin{tabular}{lcc} 
& $\begin{array}{c}\text { STLA-MP } \\
\text { (Pre-test \& Post-test) }\end{array}$ & $\begin{array}{c}\text { STPA } \\
\text { (Pre-test \& Post-test) }\end{array}$ \\
\hline Negative ranks & 0 & 0 \\
\hline Positive ranks & 3 & 4 \\
\hline Ties & 2 & 1 \\
\hline Asymp. Sig. (2 tailed) & 0.10 & 0.06 \\
\hline
\end{tabular}

P value (Asymp. Sig 2 tailed) > 0.05 yakni sebesar 0.10 untuk STLA dan 0.06 untuk STPA. Dengan demikian saat post-test tidak terjadi perubahan yang signifikan pada peserta baik dalam hal kemampuan menolak secara asertif maupun dalam kecenderungan menunjukkan perilaku asertif.

Sedangkan hasil analis statistik terhadap data pre-test dan data saat follow-up adalah sebagai berikut :

Tabel 2. Hasil Uji Wilcoxson Post-test dan Follow-up

\begin{tabular}{lcc} 
& $\begin{array}{c}\text { STLA-MP } \\
\text { (Pre-test \& Post-test) }\end{array}$ & $\begin{array}{c}\text { STPA } \\
\text { (Pre-test \& Post-test) }\end{array}$ \\
\hline Negative ranks & 0 & 0 \\
\hline Positive ranks & 4 & 5 \\
\hline Ties & 1 & 0 \\
\hline Asymp. Sig. (2 tailed) & 0.06 & 0.04 \\
\hline
\end{tabular}

P value (Asymp. Sig 2 tailed) 0.10 untuk STLA ( $\mathrm{P}>0.05)$ dan 0.04 untuk STPA $(\mathrm{P}<0.05)$, dengan demikian dapat dikatakan hasil pengukuran saat follow-up menunjukkan pengaruh program intervensi terhadap peningkatan kecenderungan partisipan untuk menunjukkan tingkah laku asertif namun tidak secara signifikan mempengaruhi peningkatan kemampuan menolak secara asertif pada partisipan.

Secara umum, program intervensi berjalan sesuai jadwal yang telah ditetapkan. Dalam sesi 1, secara umum partisipan dapat mengindentifikasi dan juga menceritakan tentang pengalaman mengalami tekanan dari teman sebaya. Bentuk tekanan teman sebaya yang pernah diterima partisipan antara lain dipaksa mengerjakan soal ujian teman, memilih suatu model baju yang tidak sesuai selera pribadi, mendapat perlakuan tidak enak dari teman karena menolak diajak pergi, dan mendapatkan ajakan dari temannya untuk bermain basket saat masa PSBB. Dalam diskusi di akhir sesi 1, partisipan 
dapat mengenali situasi yang biasanya membuat mereka sulit menolak seperti takut dijauhi teman atau dianggap penakut, memahami apa yang disebut tekanan teman sebaya, apa saja bentuknya, dan apa dampak yang dapat ditimbulkan. Selain itu seluruh partisipan juga dapat mengenali alasan yang bisa digunakan ketika hendak menolak suatu ajakan atau tekanan, misalnya karena ajakan yang diberikan dapat menimbulkan bahaya, dapat menimbulkan konsekuensi terkait performa di sekolah, atau termasuk perbuatan yang dosa.

Di awal sesi 2, seluruh partisipan mengaku belum mengenal istilah asertif. Setelah mendapatkan penjelasan tentang gaya komunikasi pasif, agresif, dan asertif, partisipan memahami bahwa gaya komunikasi yang paling efektif digunakan ketika hendak melakukan penolakan terhadap ajakan dari teman yang terasa menekan adalah secara asertif. Masing-masing partisipan memiliki pengalaman dalam menolak dengan menggunakan berbagai gaya komunikasi. P2, P3 dan P5 cenderung menggunakan gaya komunikasi pasif saat menolak. Sedangkan P4 pernah menggunakan gaya agresif dengan pergi begitu saja. P1 mengaku pernah mencoba melakukan gaya asertif namun tidak mengetahui istilahnya. Saat melakukan roleplay gaya komunikasi dalam kelompok, masing-masing partisipan sudah dapat mengenali berbagai gaya komunikasi khususnya untuk merespon ajakan atau tekanan.

Dalam sesi 3 diajarkan lima langkah penolakan yaitu mengajukan pertanyaan, mengidentifikasi masalah, menyatakan konsekuensi, menyaranan alternatif pilihan, dan beralih dari masalah atau pergi. Setelah penyampaian materi, secara umum partisipan memahami langkah-langkah yang dapat dilakukan ketika hendak melakukan penolakan. Setelah melakukan rolepay, partisipan memiliki gambaran tentang bagaimana melakukan langkah penolakan. Bagi partisipan langkah melakukan penolakan ini dirasa dapat dilakukan dalam kehidupan sehari-hari. Bagi partisipan langkah melakukan penolakan ini dirasa dapat dilakukan dalam kehidupan sehari-hari. Dari lima langkah ini, bagi P1 bagian paling menantang adalah mendeskripsikan masalah, bagi P2 adalah memberikan alternatif, bagi P3, P4, dan P5 adalah saat memutuskan untuk pergi.

Dalam sesi 4, PI membahas kembali tentang gaya komunikasi asertif dalam menolak dan kemudian melakukan latihan kembali dengan cara roleplay. Partisipan diminta untuk melakukan penolakan terhadap ajakan dari teman lain sesuai skenario yang ditentukan oleh PI. Skenario yang diberikan dalam roleplay adalah ajakan dari teman untuk makan di restoran yang ramai dalam masa PSBB dan desakan dari teman untuk tidak menggunakan masker saat berada di luar rumah. Secara umum partisipan sudah 
mampu melakukan penolakan dengan asertif mengikuti lima langkah yang sudah disampaikan sebelumnya walau masih belum sempurna. Beberapa respon yang disampaikan partisipan antara lain "memangnya kamu mau memperburuk kesehatan dan keadaan?" (P2) dan "ngapain keluar pas lagi pandemi? Kalau tidak penting tidak usah, kalau mau beli sesuatu pesan online aja kalau gak mau pakai masker" (P3). P1 dan P5 sudah dapat melakukan lima langkah penolakan secara lengkap. P2 masih melewatkan bagian memberikan konsekuensi, P4 masih belum menunjukkan kata-kata yang efektif untuk pergi dari kondisi tekanan, sedangkan P3 melewatkan bagian konsekuensi. Ketika ditanya seberapa partisipan merasa memahami lima langkah penolakan dalam skala 1-10, rata-rata partisipan menjawab merasa sudah ada di level 8-9.

Dalam pra sesi 5, PI menghubungi partisipan secara individual untuk melakukan roleplay. Skenario yang diberikan oleh PI adalah mengajak partisipan untuk keluar rumah dan berjalan-jalan ke pusat perbelanjaan tanpa alasan yang mendesak, padahal hal ini adalah hal yang tidak dianjurkan selama masa PSBB. Seluruh peserta mampu menunjukan respon penolakan, bentuk respon yang muncul dalam roleplay ini antara lain "Jangan dulu deh malah ini takutnya makin banyak yang terinfeksi" (P2), "Enggak ah, kata dokter nggak ada yang namanya new normal, ini masih banyak yang kena dan masih ada risiko ketularan" (P4). P2 dapat melakukan lima langkah penolakan dengan lengkap namun merasa sedikit kesulitan saat memberikan alternatif. P4 agak terbata-bata saat melakukan penolakan karena sempat bingung untuk membedakan antara menentukan masalah dan konsekuensinya. P1 dan P3 dapat melakukan lima langkah penolakan secara asertif dengan baik dan lancar. P5 juga dapat melakukan seluruh langkah penolakan dengan runut, namun mengaku masih merasa sulit untuk pergi beralih dari masalah ketika terus didesak. Dari hasil roleplay ini seluruh partisipan optimis mampu melakukannnya jika mendapatkan tekanan di dunia nyata.

Dalam sesi 5, PI memandu partisipan untuk me-refresh hal apa saja yang telah dipelajari selama sesi intervensi dan mengajak partisipan berdiskusi bersama agar dapat menemukan insight. Secara umum partisipan merasa mendapatkan pelajaran dan hal baru dari program intervensi ini yang akan membantu mereka dalam menjalani kehidupan kedepannya. P2 merasa selama ini tidak banyak memperhatikan alasan untuk dirinya sendiri ketika merespon ajakan atau tekanan dari teman dan lebih banyak memikirkan orang lain. P4 merasa ketika hendak menolak suatu ajakan, akan lebih mudah ketika dirinya pada dasarnya tidak menginginkan hal tersebut dibandingkan ketika hal tersebut dia inginkan tapi sedang tidak bisa dilakukaan saat ini karena kondisi pandemi. P3 
menyatakan hal penting yang dia dapatkan adalah sebelum merespon suatu ajakan, kita harus melihat dulu apa dampaknya bagi diri kita sendiri. P1 merasa sesi intervensi berjalan seru dan membuatnya mengetahui bahwa dalam berkomunikasi harus mempertimbangkan diri sendiri, orang lain, dan lingkungan sekitar. P5 menyatakan lima langkah penolakan sangat bermanfaat walau masih menantang untuk memberikan alternatif dan untuk pergi ketika terus didesak.

Hasil evaluasi secara kualitatif menunjukkan partisipan merasa program intervensi membuat mereka mengenali situasi yang kerap membuat mereka sulit untuk menolak, salah satunya yaitu adanya tekanan teman sebaya. Partisipan juga mendapatkan pemahaman tentang hal apa yang harus dipertimbangkan sebelum menerima atau menolak ajakan. Selain itu, langkah-langkah untuk melakukan penolakan secara asertif yang diajarkan dalam program dirasa bermanfaat sebagai panduan bagi partisipan ketika akan melakukan penolakan terhadap ajakan teman dalam kehidupan sehari-hari.

Saat dilakukan follow-up tiga minggu setelah sesi terakhir, dua dari lima partisipan mengaku sempat mendapatkan ajakan dari teman sebaya untuk melakukan hal yang sebaiknya dihindari dalam masa PSBB ini dan berkesempatan untuk mempraktekkan pengetahuan dan kemampuan yang didapatkan dari program intervensi. P2 sempat dihadapkan pada situasi diajak oleh teman-temannya mengikuti reuni sekolah. P3 mendapat ajakan untuk hadir dalam acara perayaan kelulusan bersama teman-teman seangkatannya. Keduanya berhasil menolak ajakan tersebut dengan memberikan alasan terkait kesehatan dan keselamatan, serta memberikan alternatif untuk menunda jadwal reuni dan perayaan kelulusan sampai situasi menjadi lebih kondusif. Meskipun ketiga peserta yang lain belum mendapatkan kesempatan untuk mempraktekkan kemampuan yang mereka dapatkan dari program intervensi saat follow-up, ketiganya merasa yakin bisa mempraktekkan kemampuan ini jika kelak dihadapkan pada situasi harus menolak tekanan dari teman sebaya.

Lebih lanjut, berdasarkan wawancara para partisipan merasakan hal yang positif dari program intervensi yang dijalankan seperti merasa senang dan terkesan (P1, P4) dan merasa mendapatkan manfaat dari sesi-sesi yang dijalankan (P2, P3, P5). Hal yang paling banyak membantu partisipan dalam proses intervensi ini adalah adanya sesi roleplay antar partisipan (P3, P4, P5). Bagi partisipan, manfaat yang dirasakan antara lain dapat menyadari pentingnya mempertimbangkan dampak tindakan yang dilakukan terhadap diri sendiri dan memahami kondisi diri sendiri (P2, P3), menjadi bekal dalam berkomunikasi dan sosialisasi dengan lingkungan pergaulan di sekolah (P1, P5, P4). 


\section{Pembahasan}

Setelah mengikuti program intervensi kelompok secara daring untuk meningkatkan kemampuan menolak secara asertif, secara umum partisipan menjadi dapat mengenali situasi yang kerap membuat mereka sulit untuk menolak, salah satunya yaitu adanya tekanan teman sebaya. Partisipan juga mendapatkan pemahaman tentang hal apa yang harus dipertimbangkan sebelum menerima atau menolak ajakan. Selain itu, langkahlangkah untuk melakukan penolakan secara asertif yang diajarkan dalam program juga dirasa bermanfaat oleh partisipan sebagai panduan ketika akan melakukan penolakan dalam kehidupan sehari-hari terutama dalam lingkungan pertemanannya. Secara keseluruhan sesi intervensi dapat berjalan dengan baik dan mendapatkan tanggapan positif dari para partisipan. Hal ini sejalan dengan pendapat Clarke, Kuosmanen, dan Barry (2015) yang menyatakan intervensi secara daring pada remaja potensial dilakukan sebagai sarana meningkatkan kesejahteraan mental dan mengurangi kemungkinan masalah kesehatan mental.

Walaupun demikian, analisis data secara statistik menunjukkan bahwa meskipun terdapat peningkatan skor STLA-MP yang dilihat dari data yang didapatkan saat post-test dan follow-up, program intervensi belum cukup efektif meningkatkan kemampuan menolak secara asertif pada partisipan. Hal ini sejalan dengan Wynn, dkk (2000, dalam Nichols, dkk. 2006) yang menemukan dalam salah satu studinya bahwa bahwa program intervensi dapat meningkatkan kemampuan menolak, namun peningkatan ini tidak secara langsung mempengaruhi perilaku partisipan secara efektif. Namun demikian berdasarkan peningkatan skor STPA yang didapat saat post-test dan follow-up, program intervensi ini ditemukan efektif meningkatkan kecenderungan perilaku asertif secara umum pada partisipan.

Beberapa hal yang diduga mempengaruhi kondisi ini antara lain jarak antar sesi yang terlalu dekat sehingga tidak semua partisipan memiliki kesempatan untuk dapat mempratekkan kemampuan melakukan penolakan secara langsung. Waktu pelaksanaan program intervensi yang bersamaan dengan masa liburan sekolah juga menjadikan intensitas interaksi para partisipan dengan teman-temannya menjadi lebih minim sehingga hal ini juga menurunkan kemungkinan partisipan untuk berada dalam kondisi menerima tekanan teman sebaya atau ajakan tertentu dan berkesempatan mempraktekkan ilmu yang didapat dari program. Hal ini sejalan dengan pendapat Gikonyo \& Njagi (2016) yang menyebutkan keberadaan teman memberikan standar perilaku bagi remaja karena apa yang dilakukan teman akan mempengaruhi remaja. Selain itu 
ditemukan bahwa partisipan yang menunjukkan kenaikan skor STLA-MP dan STPA saat post-test dan tetap stabil saat follow-up adalah mereka yang memiliki kesempatan dan berhasil untuk mempraktikkan langsung pengetahuan dan keterampilan yang diajarkan dalam program.

Program intervensi ini juga dilakukan dalam bulan-bulan awal saat pemberlakuan pembatasan sosial berskala besar (PSBB) masih ketat dan belum diberlakukan aturan new normal. Sehingga hal ini menurunkan kemungkinan para partisipan mendapatkan tekanan dari teman sebaya karena kontrol terhadap mobilitas dan aktivitas masih sangat ketat

Selain menjadi bekal untuk untuk melakukan penolakan secara asertif saat berada dalam kondisi mendapat tekanan dari teman sebaya, keterampilan dan pengetahuan yang didapat dari program intervensi juga dirasa partisipan bermanfaat dalam interaksi seharihari dengan anggota keluarga di rumah. Ketika ada hal yang tidak sesuai dengan pendapat mereka atau saat memiliki hal untuk diutarakan pada orang tua dan anggota keluara lain, para partisipan dapat mempraktekkan komunikasi secara asertif sehingga pendapat atau perasaan mereka dapat diterima dengan baik. Hal ini merupakan hasil yang positif dimana kemampuan untuk asertif merupakan kemampuan sosial yang bermanfaat secara sosial dan dalam hubungan jangka panjang (Marchezini-Cunha \& Tourinho, 2010).

Salah satu hal yang khas ditemukan dalam kelompok partisipan ini adalah munculnya bentuk alasan religius ketika melakukan praktek menolak ajakan seperti takut berdosa, takut yang dilakukan tidak berkah, dan mempertimbangkan konsekuensi di akhirat. Hal ini diduga memiliki kaitan dengan latar belakang partisipan yang berasal dari sekolah berbasis Islam sehingga nilai-nilai terkait agama terlah terinternalisasi. Menurut Ismail (2009) lembaga pendidikan berbasis agama Islam menjadi media yang kuat untuk proses internalisasi nilai-nilai ajaran agama Islam.

Secara umum berdasarkan hasil diskusi, partisipan merasa puas dan senang mengikuti program intervensi. Partisipan merasa memiliki kemampuan baru yang akan membantu mereka dalam berinteraksi sehari-hari dan menghindarkan diri mereka dari pengaruh tekanan teman sebaya yang negatif. Partisipan juga menjadi lebih memikirkan dampak pada diri sendiri, orang lain dan lingkungan ketika hendak melakukan suatu hal dimana sebelumnya kebanyakan cenderung memikirkan perasaan orang yang mengajak melakukan sesuatu. Dengan sesi yang dilakukan berkelompok, partisipan menjadi tidak merasa memiliki masalah sendiri, namun juga kesulitan mereka ternyata dialami temanteman yang lain. 


\section{Simpulan}

Program intervensi kelompok secara daring yang dilakukan berupa pelatihan berbasis experiential learning ditemukan belum cukup efektif meningkatkan kemampuan menolak secara asertif namun efektif untuk meningkatkan kecenderungan berperilaku asertif pada partisipan. Kemampuan menolak secara asertif merupakan bagian dari keterampilan interpersonal yang sebaiknya dimiliki oleh remaja untuk melindungi diri dari berbagai pengaruh negatif terutama tekanan teman sebaya. Namun demikian secara umum partisipan merasa puas dan senang mengikuti program intervensi. Partisipan merasa memiliki kemampuan baru yang akan membantu mereka dalam berinteraksi sehari-hari dan menghindarkan diri mereka dari pengaruh tekanan teman sebaya yang negatif. Pengetahuan dan keterampilan yang didapatkan dari program intervensi juga dirasa bermanfaat dalam interaksi sosial sehari-hari. Dengan sesi yang dilakukan berkelompok, partisipan menjadi tidak merasa memiliki masalah sendiri, namun juga kesulitan mereka ternyata dialami teman-teman yang lain.

\section{Saran}

Agar program intervensi dapat menjadi lebih baik jika dilakukan ulang untuk ke depannya, beberapa hal yang dapat dilakukan antara lain melakukan kerja sama dengan sekolah atau instansi tertentu untuk menjaring partisipan agar dapat lebih spesifik menggali peer pressure yang terjadi untuk satu kelompok partisipan yang lebih homogen. Kemudian dapat dipertimbangkan untuk menambah waktu jeda antar sesi dan juga jeda waktu untuk melakukan sesi follow-up agar partisipan memiliki kesempatan lebih banyak untuk mempraktekkan materi yang diberikan dalam program intervensi sehingga kemampuan untuk menolak secara asertif di kehidupan sehari-hari dapat lebih berkembang.

\section{Kepustakaan}

Badan Narkotika Nasional. 2018. "Penggunaan Narkotika di Kalangan Remaja Meningkat". 23 Juli 2020. https://bnn.go.id/penggunaan-narkotika-kalangan-remaja-meningkat/

Botvin, G. J., \& Botvin, E. M. (1992). Adolescent tobacco, alcohol, and drug abuse: prevention strategies, empirical findings, and assessment issues. Journal of Developmental and Behavioral Pediatrics.

Brown, B.B., Clasen, D.R. \& Eicher, S.A. (1986). Perceptions of peer pressure, peer conformity dispositions, and self-reported behavior among adolescents. Developmental Psychology, 22 (4), 521-530.

Burnard, P. (1996). Acquiring Interpersonal Skills. doi:10.1007/978-1-4899-7015-2 
Clarke, A. M., Kuosmanen, T., \& Barry, M. M. (2015). A systematic review of online youth mental health promotion and prevention interventions. Journal of youth and adolescence, 44(1), 90-113.

Dickson, Sydnee. (2016). Utah's Safe and Drug-Free Schools and Communities PK-12 Prevention Program. Salt Lake City : Utah State Board of Education.

Dodge, K. A., Lansford, J. E., \& Dishion, T. J. (2006). The Problem of Deviant Peer Influences in Intervention Programs.

Epstein, J. A., Botvin, G. J., Diaz, T., Williams, C., \& Griffin, K. (2000). Aggression, victimization and problem behavior among inner-city minority adolescents. Journal of Child \& Adolescent Substance Abuse, 9(3), 51-66.

Gikonyo, R. W., \& Njagi, K. (2016). The Influence of Demographic Factors on Peer pressure among Secondary School Adolescents in Nyahururu Laikipia County. Research on Humanity and Social Sciences. 6(22). 2225-0484.

Herrero, R., Mira, A., Cormo, G., Etchemendy, E., Baños, R., García-Palacios, A., ... Botella, C. (2019). An Internet based intervention for improving resilience and coping strategies in university students: Study protocol for a randomized controlled trial. Internet Interventions, 16(December 2017), 43-51. https://doi.org/10.1016/j.invent.2018.03.005

Ismail, W. (2009). Analisis Komparatif Perbedaan tingkat religiusitas siswa di lembaga pendidikan pesantren, MAN, dan SMUN. Lentera Pendidikan: Jurnal Ilmu Tarbiyah dan Keguruan, 12(1), 87-102.

Leader, E. (1991). Why adolescent group therapy?. Journal of Child and Adolescent Group Therapy, 1(2), 81-93.

Lebedina M. M., Lotar, M., \& Ricijaš, N. (2011). Peer pressure in Adolescence-Boundaries and Possibilities. Saarbrucken, LAP LAMBERT Academic Publishing.

Marchezini-Cunha, V., \& Tourinho, E. (2010). Assertiveness and self control: A behavioranalytic interpretation. Psicologia: Teoria E Pesquisa, 26, 295-303.

Miller-Day, M. A., Alberts, J., Hecht, M. L., Trost, M. R., \& Krizek, R. L. (2000). Adolescent relationships and drug use. Psychology Press.

Nichols, T. R., Graber, J. A., Brooks-Gunn, J., \& Botvin, G. J. (2006). Ways to say no: refusal skill strategies among urban adolescents. American Journal of Health Behavior, 30(3), 227-236.

Rahel (2014). Asosiasi antara Tekanan Teman Sebaya, Emosi Malu, dan Emosi Bersalah pada Remaja. Skripsi. Fakultas Psikologi Universitas Indonesia.

Ramasamy, P., Krishnan, S., \& Tee, Y. L. (2020). General relationship between conformity and peers pressure among form 3 students of secondary school in Johor Bahru. Muallim Journal of Social Sciences and Humanities, 16-28.

Richter, M. (2010). Risk behaviour in adolescence. Springer Fachmedien. 
Philanthropy Journal of Psychology

Vol 5 Nomor 1 (2021), 1-16

ISSN 2580-6076 (Print), ISSN 2580-8532 (Online)

Sa'diyah, S. H. (2017). Studi Kasus Perilaku Kenakalan Remaja Di Sekolah Yang Berlandaskan Islam (Doctoral Dissertation, Universitas Muhammadiyah Gresik).

Unayah, N., \& Sabarisman, M. (2016). Fenomena kenakalan remaja dan kriminalitas. Sosio informa, 1(2).

UNICEF INDONESIA. (2020). Situasi Anak Indonesia 2020. 23 Juli 2020. https://www.unicef.org/indonesia/sites/unicef.org.indonesia/files/202007/Situasi-Anak-di-Indonesia-2020.pdf .

Utama Yoga, 0. (2016). Perbedaan Tingkat Moral Siswa Antara Sekolah Berbasis Islam Dengan Sekolah Umum. Skripsi. Universitas Muhammadiyah Surakarta).

Zulkaida, A. (2004). Pelatihan Asertif untuk Meningkatkan Perilaku Asertif Pada Mahasiswa (Pendekatan Kognitif-Tingkah Laku). Skripsi. Universitas Indonesia. 